\title{
A RELIGIÃO INTIMISTA DE ROUSSEAU: UM DEBATE SOBRE A RELAÇÃO ENTRE CONSCIÊNCIA, RAZÃO E CONHECIMENTO
}

\author{
Manoel Jarbas Vasconcelos Carvalho ${ }^{1}$
}

\section{Resumo:}

\begin{abstract}
A discussão concernente à relação entre a razão e a consciência moral no pensamento rousseauniano anima os longos debates entre os estudiosos de Rousseau. A influência religiosa que reivindica a primazia da consciência moral sobre a razão a que Jean-Jacques esteve exposto no decorrer de sua vida foi amplamente estudada por Pierre-Maurice Masson em La religion de J.-J. Rousseau: la formation religieuse de Rousseau. Sob outro aspecto, autores como Georges Beaulavon, Émile Bréhier e especialmente Robert Derathé, em Le rationalisme de Jean-Jacques Rousseau, compreenderam a obra do genebrino sob o prisma do racionalismo de Descartes e Malebranche. O objetivo desta pesquisa, além de trazer à tona a discussão sobre esses estudos, é mostrar que a razão e a consciência moral coexistem e interdependem-se no interior do pensamento de Rousseau.
\end{abstract}

Palavras-chaves: Rousseau. Religião. Razão. Consciência. Conhecimento.

\section{LA RELIGION INTIMISTE DE ROUSSEAU: UN DÉBAT SUR LA RELATION ENTRE CONSCIENCE, RAISON ET CONNAISSANCE}

\begin{abstract}
Résumé:
La discussion concernant la relation entre la raison et la conscience morale dans la pensée de Rousseau anime les longs débats entre les spécialistes roussistes. L'influence religieuse qui revendique la primauté de la conscience morale sur la raison à laquelle Jean-Jacques a été exposé durant le cours de sa vie a été longuement étudiée par Pierre-Maurice Masson dans La religion de J.-J. Rousseau: la formation religieuse de Rousseau. Sous tout autre aspect, des auteurs comme Georges Beaulavon, Émile Bréhier et notamment Robert Derathé, dans Le rationalisme de Jean-Jacques Rousseau, ont compris l'œuvre du genevois sous l'angle du rationalisme de Descartes et Malebranche. Le dessein de cette recherche, outre relancer la discussion touchant ces études, il est de montrer que la raison et la conscience morale coexistent et sont corrélées dans la pensée de Rousseau.
\end{abstract}

Mots-clés: Rousseau. Religion. Raison. Conscience. Connaissance.

\section{A influência religiosa de Rousseau: a supremacia da consciência sobre a razão}

Em sua extensa obra, Masson mostra que Rousseau é no Setecentos a resposta sentimentalista às Luzes, com sua inabalável crença na razão e em seu progresso. Temas como o "retorno à natureza", a "fadiga da razão" e as "evidências do coração" fazem de Rousseau, segundo Masson (1916), um profeta e um intérprete do século XVIII. Masson (1916) lembra que, desde sua tenra idade de estudos intensos,

1 Pós-Doutor em Filosofia pela Universidade Federal do Rio Grande do Norte - UFRN. Doutor em Educação com ênfase em Filosofia da Educação pela Universidade Federal do Ceará - UFC. Mestre em Ética e Filosofia Política e Graduado em Filosofia pela Universidade Estadual do Ceará - UECE. E-mail: jarbasvc@gmail.com. 
iniciada na casa da Sra. de Warrens, os objetivos das especulações filosóficas de Rousseau estavam voltados a aperfeiçoar o espírito sem dissociar disso seu perfeccionismo moral e as suas crenças religiosas. Assim, o duplo desejo de Rousseau, afirma ele, “[...] era, em adquirindo conhecimentos, restabelecer seu justo valor para as certezas da religião e para a prática da virtude” (MASSON, 1916, p. 91).

Esse desejo da perfectibilidade moral, em que é necessário compreender o universo e encontrar uma regra de vida segura, será o elã de toda a teoria rousseauniana (MASSON, 1916). Para Masson (1916), essa atitude de um autêntico moralista denota desde já a desconfiança de Rousseau com relação à razão, ao mesmo tempo que a prepara para a obediência ao sentimento. A insuficiência do espírito, a potência enganadora do orgulho e a fadiga da razão serão denunciadas, segundo Masson (1916), pelo Vigário de Rousseau em sua Profissão de fé. Nesse livro, afirma Masson (1916), o Deus do coração e da natureza, da natureza organizada e consoladora, será, para Rousseau, o recurso supremo do homem bom contra a mecânica social.

A obra de Masson (1916) é orientada pela crítica de Rousseau à razão e, ao mesmo tempo, pelo elogio do genebrino ao sentimento interior. Masson (1916) salienta que, em várias passagens dos escritos de Rousseau, o filósofo deixa transparecer a soberania do sentimento sobre o espírito. Um exemplo emblemático é a conhecida passagem da Profissão de fé em que Rousseau (2014, p. 411-412) exalta a importância da consciência frente à razão: "Consciência! Consciência! Instinto divino, imortal e celeste voz [...]; sem ti nada sinto em mim que me eleve acima dos animais, a não ser o triste privilégio de perder-me de erros em erros com o auxílio de um entendimento sem regra e de uma razão sem princípio”. Masson (1916) sublinha que Rousseau exalta a consciência tanto para combater a "razão raciocinante" dos filósofos iluministas como para sugerir ao homem o retorno à sua natureza interior. A Profissão de fé é profícua desses exemplos; nela Rousseau (2014, p. 405) afirma que "[...] a consciência é a voz da alma, as paixões são a voz do corpo [...]; a razão nos engana [...]; a consciência nunca engana. Ela é o verdadeiro guia do homem; [...] quem a segue obedece à natureza e não tem medo de se perder". Com base nisso, Rousseau (2014) aconselha os seus contemporâneos para que sejam mais simples e menos vaidosos. No entanto, para que isso aconteça, “[...] devemos nos limitar aos primeiros sentimentos que encontramos em nós mesmos, já que é sempre a eles que o estudo nos leva quando não nos desorientou" (ROUSSEAU, 2014, p. 411).

\begin{tabular}{|l|l|l|l|l|}
\hline Qovista Dialectus & Ano 8 & n. 15 & Agosto - Dezembro 2019 & p. $203-217$ \\
\hline
\end{tabular}


Sobre a relação entre a razão e a consciência, Masson (1916) assevera apontando a influência de Marie Huber sobre Rousseau - que a consciência é a verdadeira chave do conhecimento. Para a teóloga protestante, lida atentamente por Rousseau, o conhecimento é produzido por meio da consciência, e é ela que determinará - antes mesmo da razão - o "certo" e o "errado" para que possamos, a partir disso, extrair com segurança o verdadeiro conhecimento das coisas ${ }^{2}$. Esse apoio sobre a consciência protegerá Rousseau dos sofismas da razão. Segundo Masson (1916), JeanJacques, sob influência de Marie Huber, fará do sentimento interior um verdadeiro instinto, superior a todos os raciocínios, dotado de uma segurança da intuição que dispensará qualquer outra orientação anterior. A invocação ao sentimento marcará a literatura teológica do dix-huitième siècle, tanto como em reação à filosofia de Descartes como em resposta ao empirismo de Locke. Contra o cartesianismo, ressalta Masson (1916), o Abbé de Pluche ${ }^{3}$ afirmará que a metafísica do cogito, descolada das evidências sensíveis do bom senso, que são produzidas pela intuição moral do sentimento interior, nada valerá e não passará de uma regra insuficiente. Por conseguinte, em oposição ao empirismo, “[...] os defensores da consciência [como Marie Huber] serão tentados a subtrair-se das investigações positivas e fazer uma espécie de 'faculdade à parte da alma' como de um sentido íntimo, seguro e infalível ${ }^{4 \text { " }}$ (MASSON, 1916, p. 237).

A recusa, por parte de pietistas e jansenistas, como Marie Huber e o Abbé de Pluche, tanto do cartesianismo, com sua plena confiança na razão, como do empirismo, que subtrai da busca da verdade o sentiment intérieur, será aceita por Rousseau. A filosofia de Descartes e o empirismo de Locke, salienta Masson (1916), serão considerados pelos dois teólogos com “ateísmo”, ou por relegarem Deus a um

2 Marie Huber nas Lettres sur la religion essentielle à l'homme não utiliza o termo conscience, mas a palavra sentiment para designar o conhecimento íntimo presente no homem. Masson (1916) utiliza a palavra conscience equiparando-a ao sentiment tomando como perspectiva o pensamento de Rousseau onde os dois termos são análogos. Sobre a importância do sentiment no livro de Marie Huber (1739), consultar o artigo de Pitassi (1995). Recomendamos também o artigo de Kawauche (2012).

3 Padre francês, jansenista. Autor do Spectacle de la nature. Sobre a biografia de Antoine Pluche ou l'Abbé de Pluche (1688-1761) consultar a Encyclopédie Universalis de France, disponível em: <http://www. universalis.fr/encyclopedie/antoine-pluche/>.

4 Marie Huber (1739) considera a experiência importante porque é através dela que o homem pode experimentar o sentimento de sua existência. No entanto, ao contrário dos empiristas que se valem das investigações positivas para provar a validade do conhecimento (subtraindo-se das evidências do sentiment), Huber (1739) une a experiência a um sentimento seguro e infalível não apenas para provar à existência do homem, mas sua íntima ligação com Deus.

\begin{tabular}{|l|l|l|l|l|}
\hline Qovista Dialectus & Ano 8 & n. 15 & Agosto - Dezembro 2019 & p. $203-217$ \\
\hline
\end{tabular}


segundo plano ou pôr o desprezarem em suas filosofias. Rousseau não compartilhará dessas opiniões, porém procurará resgatar o papel do divino em sua teoria do conhecimento. Junto com a defesa da consciência, ele fará a defesa de Deus. Rousseau (2005c) reconhece que Deus está em cada um e que devemos buscar a verdade em nós mesmos, pois não é pela razão que se chega a Deus, e sim pelos sentimentos. Parágrafos depois, ele irá unir sua teoria em defesa de Deus à sua definição da consciência. Ele diz que a verdade moral residente na alma de todos os homens é anterior à vida social e que ela, a consciência, é a regra involuntária da qual todos nós extraímos os julgamentos sobre o bem ou o mal (ROUSSEAU, 2005c).

Rousseau é coerente com a sua teoria da conscience, observa Masson (1916), quando alega que a existência de Deus é, por excelência, uma "verdade do sentimento", ou, mais exatamente, aquela direção para a qual todas as outras convergem para se confirmar. Na filosofia de Rousseau, salienta ele, o coração - de élan en élan reclama uma garantia suprema. Essa teologia do coração, diz Masson (1916, p. 158), "[...] desconfia da filosofia e da razão, potências de dúvida, de sofismas, que nos jogam [nas incertezas da razão raciocinante $\left.{ }^{5}\right]$ ”; o melhor é, segue Masson, “[...] regressar ao coração como a uma 'fonte primitiva' e regenerar o pensamento regenerando o coração".

Consoante Masson (1916, p. 107-108), Rousseau incorporou do Abbé de Pluche, Saint-Aubin ${ }^{6}$ e Claville ${ }^{7,8}$ “[...] a [crítica à] inutilidade vã dos sistemas, [o reconhecimento da] indigência pretensiosa da razão quando quer ultrapassar as limitações da experiência [e] a [afirmação da] supremacia do coração [...] e da virtude [...]”. Para Rousseau, nas palavras de Masson (1916, p. 108), “[...] o primeiro dos conhecimentos é o conhecimento de Deus e dos seus deveres [...], toda ciência é vã se não nos orientar para a prática do bem”. Essa última intenção de motivos será um dos propósitos de Rousseau no Discurso sobre as ciências e as artes. Nesse livro, Rousseau

5 Segundo Masson (1916), o termo "razão raciocinante" diz respeito à crítica do dramaturgo francês Pierre Carlet de Chamblain de Marivaux (1688-1763), lida e absorvida por Rousseau, sobre a mania de sistemas da filosofia francesa. Essa crítica quer atingir principalmente o cerne do dogmatismo filosófico e sua crença na superpotência da razão.

6 Barão de Laney, conselheiro do parlamento de Paris e desembargador. Gilbert Charles Le Gendre (Marquis de Saint-Aubin-sur-Loire) (1688-1746) é autor do Traité de l'opinion. A obra está disponível em <https:// archive.org/details/traitdelopinion00conggoog>.

7 Teólogo católico e humanista. Autor do Traité du vrai mérite. Sobre Charles-François-Nicolas Le Maître de Claville (1670-1740), consultar Dornier (2009).

8 Estes autores ligados ao humanismo católico forneceram diversas contribuições intelectuais ao Mercure de France. Rousseau os lera pela primeira vez em sua estada na Charmettes de propriedade da Sra. de Warrens entre os anos de 1736 e 1742. Sobre isso, ler Masson (1916), capítulo IV, parte II.

\begin{tabular}{|l|l|l|l|l|}
\hline Rovita Dialectus & Ano 8 & n. 15 & Agosto-Dezembro 2019 & p. $203-217$ \\
\hline
\end{tabular}


quer ajudar o homem a redimensionar sua inteligência para que ele faça da razão um bom uso, pois nossa inteligência, entende ele, deve ser eivada primeiramente de uma intencionalidade moral que possa não apenas conhecer, mas, sobretudo, ajudar-nos a viver.

\section{A crítica à concepção sentimentalista de Masson e o racionalismo de Rousseau}

Masson foi acusado, principalmente por Georges Beaulavon em La philosophie de J.-J. Rousseau et l'esprit cartésien, e por Robert Derathé, em Le rationalisme de Jean-Jacques Rousseau, de pintar um Rousseau irracionalista, demasiado sentimental e pouco ligado, ou quase completamente avesso, às tradições do racionalismo de Descartes e de Malebranche. As concepções desses dois autores são diferentes das opiniões de Masson quanto à relação entre a razão e a consciência moral na filosofia de Jean-Jacques. Embora Masson (1916) reconheça um teor racional no pensamento de Rousseau ${ }^{9}$, ele não diminui a supremacia da consciência sobre a razão posta no interior do pensamento rousseauniano.

As críticas de Beaulavon e de Derathé à interpretação sentimentalista da filosofia de Rousseau feita por Masson fazem-nos entender a dimensão racionalista do pensamento de Jean-Jacques. Ao criticar a demasiada importância do sentimento interior ou do coração em oposição à razão, Beaulavon (1937) diz que Masson (1916) traduziu a obra de Rousseau sob um viés ao mesmo tempo sentimental e místico. Sob um outro aspecto, ao opor o sentimentalismo de Rousseau ao cartesianismo, Masson (1916), segundo Beaulavon (1937), inscreveu o pensamento rousseauniano ao lado do utilitarismo pragmático ao qual o genebrino claramente se opunha ${ }^{10}$.

Derathé (2011) ampliará as críticas à interpretação sentimentalista do pensamento de Rousseau. Em Le rationalisme de Rousseau, ele afirma que o genebrino não se opõe ao racionalismo, e sim ao dogmatismo. Em seguida, diz que Rousseau não nos encoraja a nos abstermos de usar a razão, mas nos aconselha a aprendermos a bem usá-la (DERATHÉ, 2011). A intenção de Derathé (2011) é mostrar que as duas faculdades, a razão e o sentimento, não se dissociam ou se sobressaem no pensamento

9 No capítulo IV, parte III, do seu livro sobre a formação religiosa de Rousseau, Masson (1916) fala sobre o breve surto racionalista do genebrino e, em seguida, do seu retorno ao cristianismo.

10 Podemos encontrar essa crítica em Beaulavon (1937) e em Derathé (2011). Sobre esse debate inserido na obra de Masson, ler especialmente o capítulo VII, páginas 235 a 237, de sua obra.

\begin{tabular}{|l|l|l|l|l|}
\hline Rovista Cialectus & Ano 8 & n. 15 & Agosto - Dezembro 2019 & p. $203-217$ \\
\hline
\end{tabular}


de Rousseau. Na Carta ao Sr. de Franquières, Rousseau constrói duas concepções diferentes do sentimento interior: a primeira diz que nem sempre os homens estarão dispostos a escutar a voz da razão, sendo necessária a ajuda do sentimento; e a segunda conclui que, graças ao sentimento, nós podemos confirmar as verdades que a razão não nos faz conhecer. Para Derathé (2011), se interpretadas corretamente, ambas as concepções nos fazem reconhecer que o chamado ao sentimento não exclui a voz da razão, mas a completa e a confirma.

Derathé (2011) observa que Rousseau não coloca o sentimento em oposição à razão, tampouco lhe dá preferência. A razão permite, quando consciente de seus limites, recomendar o uso do sentimento para nos livrar do estado de dúvida. Na Profissão de fé, Rousseau assegura que sua regra de se entregar ao sentimento mais do que à razão é confirmada pela razão mesma. Nós podemos, portanto, segundo ele, fazer apelo ao sentimento interior sem cessar de ter uma atitude racional. Ao garantir, no escrito Fragmentos sobre Deus e a Revelação, que Deus pôs sabedoria em todos os espíritos e os gravou no fundo dos corações de todos os mortais, Rousseau (2005d) sustenta que na alma humana coexistem duas faculdades, uma racional e outra intuitiva, que se beneficiam e se socorrem mutuamente.

A prova dessa dependência podemos encontrar ainda no referido escrito. Assim, escreve Rousseau (2005d, p. 196-197), “[Deus,] Tiraste-me do nada, deste-me a existência, me dotaste de uma alma racional, gravaste no fundo de meu coração as leis cujo cumprimento vinculaste à de uma eterna felicidade; leis plenas de justiça e de doçura, cuja prática tende a tornar-me feliz já nesta vida”. Rousseau (1999b, p. 214) realça o valor da virtude e o confirma, dizendo que a virtude é a " [...] ciência sublime das almas simples e está gravada em todos os corações, basta voltar-se para si mesmo e ouvir a voz da consciência no silêncio das paixões". Como vimos, Rousseau defende que toda ciência é vã se não puder produzir o bem. Para Derathé (2011, p. 107), Rousseau não exclui a razão da vida moral, pois o sentimento sozinho não funda nem a virtude nem a lei natural, porém “[...] à razão [também] é necessário juntar o sentimento [...]; nossa conduta procede sempre de um impulso". Com Rousseau, conforme Derathé (2011), a sensibilidade (moral e sensorial) passa ao primeiro plano da vida moral. É deste duplo movimento, das sensações para a razão e da razão para as sensações, que depende, segundo Rousseau, o desenvolvimento do conhecimento humano (DERATHÉ, 2011).

\begin{tabular}{|l|l|l|l|l|}
\hline Qovista Dialectus & Ano 8 & n. 15 & Agosto - Dezembro 2019 & p. $203-217$ \\
\hline
\end{tabular}


Para Rousseau, como observa Derathé (2011), o desenvolvimento das nossas capacidades cognitivas comanda nossos sentimentos: estes se encontram para o mesmo sob a dependência das nossas faculdades intelectuais. As afeições sociais não se desenvolvem em nós sem as luzes, diz o genebrino (ROUSSEAU, 2005d). Todos os nossos sentimentos sociais obedecem a essa lei: há sempre um progresso ordenado de nossas inclinações primitivas, correspondendo à ordem segundo a qual se desenvolvem nossas faculdades intelectuais. No Emílio, Rousseau insiste igualmente sobre os sentimentos intelectuais que pertencem ao sentimento do amor e mostra que esse sentimento não pode se desenvolver no homem antes que ele não saiba mensurar seu julgamento, bem como comparar e fazer uso de sua razão. No Livro IV, ele pontua que: “[...] É preciso tempo e conhecimentos para nos tornarmos capazes de amar; só amamos após ter julgado, só preferimos após ter comparado [...]; [e], embora seus arroubos nos desorientem [...], essa escolha que se põe em oposição à razão vem-nos dela" (ROUSSEAU, 2014, p. 290).

Nós observamos, sublinha Derathé (2011), que o sentimento, para Rousseau, não se reduz "ao puro movimento da natureza"; ele comporta, na realidade, dois momentos: um impulso natural que é inato e os conhecimentos que nos são adquiridos. Para que um sentimento verdadeiro se forme, é necessário que um impulso natural venha se juntar aos conhecimentos que são obra da reflexão. Derathé (2011) diz que não existem conhecimentos nem ideias inatas para Rousseau. Jean-Jacques, como um discípulo de Condillac, para quem o conhecimento é sempre adquirido e está ligado à ordem intelectual, acredita que o progresso do sentiment intérieur permanece preso às nossas capacidades cognitivas (DERATHÉ, 2011).

Derathé (2011, p. 111) mostra a diferença entre o princípio imediato da consciência - impulso primitivo - e a consciência completa, desenvolvida e tornada ativa pelo uso da razão: "O sentimento, que é inato em nós, não pode se manifestar antes que a razão nos faça conhecer o objeto ao qual ela se aplica". Do contrário, a razão no homem é formada por várias relações morais, que a sua consciência deve ativar. Como todo impulso natural, a consciência é independente da razão, desde o princípio, porque sua presença em nós não resulta do conhecimento que nós podemos adquirir por meio da razão, contudo, sem esses conhecimentos, ela "seria eternamente inativa”. Portanto, avalia Derathé (2011, p. 111): “[...] a atividade da consciência está ligada à da razão". A consciência que nos faz amar um e outro, independentemente da

\begin{tabular}{|l|l|l|l|l|}
\hline Qovista Dialectus & Ano 8 & n. 15 & Agosto - Dezembro 2019 & p. $203-217$ \\
\hline
\end{tabular}


razão, não pode se desenvolver sem ela; “[...] a consciência e a razão se complementam", diz ele (DERATHÉ, 2011, p. 111).

Nesse sentido, a consciência não é destinada a substituir a razão, porque esta é a condição mesma de sua atividade. Basta lembrarmos que "um ser privado de razão é incapaz de adquirir o conhecimento do bem". Desse modo, consoante Derathé (2011), a consciência, a razão e a liberdade são faculdades inseparáveis na filosofia de Rousseau e servem para conduzir o homem à justiça e à virtude.

\section{O perspectivismo e a dependência entre a razão e a consciência em Rousseau}

Masson e Derathé se opõem ao definir no homem a sua faculdade de julgar e, portanto, de conhecer. Para Masson (1916), a consciência é protagonista na obra de Rousseau; é ela que julga o "certo" e o "errado", o "bem" e o "mal" das experiências advindas do mundo exterior. Essa possibilidade interpretativa, por parte de Masson, darse-á em três momentos sucedâneos das Cartas morais, em que Rousseau afirma a primazia da consciência sobre a razão. Primeiro, Rousseau (2005c) observa que ela está presente no interior dos homens e é anterior à vida social; a consciência é a regra involuntária, da qual os homens extraem todos os julgamentos sobre suas ações, sejam elas boas ou más. Segundo, para Rousseau (2005c), o sentir é anterior ao conhecer. A sensibilidade é para o homem, assevera ele, um produto da natureza e da consciência moral que nos foi entregue por Deus para julgar o "bem" e o "mal" segundo os nossos próprios princípios. Por fim, Rousseau (2005c) sustenta, mediante sua teoria da consciência moral, que das coisas à consciência, por mais que as ideias nos venham de fora, ou seja, pela percepção dos sentidos, os sentimentos que as avaliam estão em nosso interior, sendo por meio deles que conhecemos o que é conveniente ou não para nós. Masson (1916) faz dessas observações de Rousseau, como veremos, a garantia da autoridade da consciência sobre a razão, ou, mais exatamente, da moral sobre o espírito.

A consciência defendida por Rousseau, consoante Masson (1916), é verdadeira e universal ao mesmo tempo, porque está em todos os homens, como um laço de Deus em suas almas. Conhecer, portanto, não se revela como um frio esquema mental de análise da razão que se desdobra sobre o mundo exterior, e sim através de uma elevada carga moral que deve provir do sentimento interior. Rousseau não faz apelo à consciência em vão, declara Masson (1916), pois, se “a razão nos engana, a

\begin{tabular}{|l|l|l|l|l|}
\hline Qovista Dialectus & Ano 8 & n. 15 & Agosto - Dezembro 2019 & p. $203-217$ \\
\hline
\end{tabular}


consciência jamais poderá nos enganar”. Sobre isso, Rousseau (2005c) é tácito ao afirmar que as noções do "bom", do "justo" e do "honesto" são universais e se formam no estreitamento de cada alma com Deus, como um só elã que liga cada homem ao seu semelhante.

Essa interpretação do protagonismo da consciência na obra de Rousseau (2005c) nos dá a entender, no livro de Masson (1916), que a razão deve estar subordinada à consciência; ou que por momentos ela (a consciência) tenha necessidade da interdição da razão para melhor prover o seu êxito de julgar (o que é "bom", "justo" e "honesto") e, por isso, de conhecer. Nesse último caso, Rousseau já havia constatado a filiação ou a contaminação da razão pelos preconceitos da educação e pelo dogmatismo das seitas filosóficas do seu tempo. No primeiro, porém, o papel ativo da consciência provará sua conduta superior frente à razão, que teria apenas a função de juntar sensações e formar ideias, exercício completamente secundário ante a atividade primordial da consciência. "A maneira de formar ideias é o que dá um caráter ao espírito humano" (ROUSSEAU, 2014, p. 275). Essa definição que Rousseau (2014) dá ao espírito nas últimas páginas do Livro III do Emílio soará, para os defensores da consciência, como um ato mecânico e inteiramente formal do intelecto. Mesmo que, em linhas depois, Rousseau (2014) afirme que a razão julga, compara e avalia as sensações que lhe provêm dos sentidos, para formar as ideias, essas de nada valeriam sem o sentimento interior que as valida e lhes dá, portanto, sentido.

Cassirer (1999), em concordância com as teses de Masson (1916), faz uma elaborada analogia entre "sensação", "razão" e "sentimento" no interior da teoria do conhecimento de Rousseau. Primeiramente, ele diz que "[...] A palavra 'sentiment' possui uma conotação ora no sentido naturalista, ora no sentido da mera sensação [Empfidung], ora no sentido do julgamento e da decisão moral [...]. Para Rousseau o 'sentiment' é ora uma ação psíquica, ora uma ação da alma” (CASSIRER, 1999, p. 105). Para Cassirer (1999), o processo de compreensão da realidade, capaz de unir as inúmeras sensações que temos dela e dar-lhe um sentido, só é possível através do sentimento. Só o julgamento (que é sentiment) pode nos dar acesso a uma região inatingível da consciência que não pode ser captada nem pela mera sensação nem pela força lógica da razão (CASSIRER, 1999). “[...] Nenhum engano ocorre no mero ato de sofrer uma impressão; ele surge somente quando o espírito se comporta de maneira ativa ante ele [...], sobre o 'ser-assim' e o 'ser-diferente' do objeto que corresponde à

\begin{tabular}{|c|c|c|c|c|}
\hline Qovista Dialectus & Ano 8 & n. 15 & Agosto - Dezembro 2019 & p. $203-217$ \\
\hline
\end{tabular}


impressão" (CASSIRER, 1999, p. 106). Cassirer (1999, p. 107) relativiza a razão e dá ao sentimento o estatuto de uma plena abertura do ser frente ao eu que o avalia: “[...] é no querer, e não no pensar, que se revela a verdadeira essência do eu [...]”.

A razão é relativa, e a consciência (que é sentiment) deve orientá-la; essa é uma outra intuição possível que podemos extrair do livro de Masson (1916). As inúmeras influências dos teólogos lidos por Rousseau dão ao leitor da obra a ideia de que a "razão raciocinante" dos filósofos iluministas depõe contra a universalidade da consciência. E, de fato, não são poucas as referências de Rousseau sobre isso. Em Cartas morais, JeanJacques deduz do sentiment a fonte de todos os prazeres; para ele, a filosofia abafa a voz da natureza interior. Na Profissão de fé, ele alega que "[...] o testemunho dos homens, no fundo, é apenas o da minha própria razão e nada soma aos meios naturais que Deus me deu para conhecer a verdade" (ROUSSEAU, 2014, p. 422). E, na Carta a Franquières, o genebrino é tácito, ao afirmar que, “[...] se suprimíssemos o sentimento interno, já não restariam mais traços da verdade sobre a terra [...], todos nós nos tornaríamos joguete das opiniões mais monstruosas [...]” (ROUSSEAU, 2005b, p. 183).

Derathé (2011) se opõe às alegações de Masson (1916) e do que delas podemos deduzir. Para ele, a interpretação sentimentalista de Masson sobre a obra de Rousseau provém de uma má interpretação dos seus conceitos. Masson (1916), ao anatematizar ou relegar a razão a um plano de fundo secundário, no pensamento de Rousseau, confunde a razão (entendimento) com a razão dogmática (dos philosophes). Para Derathé (2011), como vimos, a razão tem como principal função o julgar, sendo que a consciência deve funcionar como o seu complemento. Rousseau (2014) confirma isso ao dizer que a consciência não pode desenvolver-se sem o auxílio da razão. É o entendimento que dá moralidade às nossas ações. Além disso, consoante Derathé (2011, p. 67), o sentimento interior não produz uma garantia suficiente de valor objetivo do nosso conhecimento, "Tanto que uma verdade demonstrada é verdadeira para todos os espíritos, a prova do sentimento só vale para si e não convence um outro". Derathé (2011), com isso, depõe contra a universalidade objetiva do sentimento interior, o que é confirmado por Rousseau (2014, p. 56) no Emílio: "Só a razão nos ensina a conhecer o bem e o mal. A consciência nos faz amar a um e a odiar ao outro [...]". A perspectiva de Masson (1916), referente à relatividade da razão e da infalibilidade da consciência, inverte-se; a consciência, nessa nova perspectiva, é relativa, e a razão é que deve orientála.

\begin{tabular}{|l|l|l|l|l|}
\hline Qovista Dialectus & Ano 8 & n. 15 & Agosto - Dezembro 2019 & p. $203-217$ \\
\hline
\end{tabular}


Derathé (2011) promove, com relação à interpretação de Masson (2016), uma verdadeira reviravolta epistemológica, que tem na obra de Rousseau o seu objeto interpretativo. Derathé (2011), mesmo afirmando a importância da consciência como auxiliar da razão, não deixa de ressaltar que, em várias partes da obra de Rousseau, a consciência é relativa e está subordinada à autoridade da razão. As duas teses serão confirmadas por Starobinski (2011). Em Os problemas da autobiografia, se é certo que o sentimento de si deverá anunciar a verdade, Starobinski (2011), assim como Derathé (2011), anuncia o relativismo do sentimento. Ele diz que "Sem dúvida, o ato do sentimento que funda o conhecimento de si não tem jamais o mesmo conteúdo [...]. $\mathrm{O}$ ato do sentimento é indefinidamente renovável [...] e adquire um valor inaugural" (STAROBINSKI, 2011, p. 246). Sobre a segunda tese, no capítulo VIII, embora Starobinski (2011, p. 283) também enfatize o negativo da razão na obra de Rousseau, ele diz que no Emílio “[...] o pensamento refletido fornece a prova do poder ativo que faz do homem um ser autônomo e livre [...]”.

Na Carta a Beaumont, Rousseau dá provas da autoridade da razão sobre a consciência. Ao descrevê-la, ele observa que “[...] a consciência só se desenvolve e age em conjunto com as luzes do homem. E só graças a essas luzes que ele atinge um conhecimento da ordem, e é só quando a conhece que sua consciência o leva a amá-la" (ROUSSEAU, 2005a, p. 48). Rousseau (2014, p. 411) afirma que o homem não tem um conhecimento inato do bem, "[...] mas, assim que a sua razão faz com que a conheça, na sua consciência leva-o a amá-lo, [e] é este sentimento que é inato". Esse agir em conjunto entre a razão e a consciência é sempre conduzido pela razão, sublinha Derathé (2011). Ao contrário de Masson (1916), Derathé (2011) não confundirá a razão (faculdade de jugar, entendimento) com a razão dos filósofos iluministas (a razão raciocinante). Para Derathé (2011), na teoria de Rousseau, a razão é da ordem do conhecimento e a consciência é da ordem dos sentimentos. A consciência não realiza julgamentos, mas se restringe à ordem dos sentimentos (DERATHÉ, 2011).

Essa virada epistemológica, em relação aos defensores da consciência, parte da crítica à razão raciocinante, e não ao entendimento. Starobinski (2011, p. 61) sustenta que a razão e o sentimento revelam-se, pois, no pensamento de Rousseau, perfeitamente conciliáveis: “[...] Rousseau acusa apenas a razão raciocinante, que inspira 'os insensatos juízos dos homens'. Essa razão instrumental aprisiona os homens na subjetividade turva da opinião e da ilusão [...]; as falsas clarezas do raciocínio comum são um contrassenso".

\begin{tabular}{|l|l|l|l|l|}
\hline Qovista Dialectus & Ano 8 & n. 15 & Agosto - Dezembro 2019 & p. $203-217$ \\
\hline
\end{tabular}


De maneira semelhante, Goyard-Fabre (2001) faz essa distinção conceitual; para ela, a razão racional (rationelle) - teórica e especulativa - é diferente da razão razoável (raisonnable) - prática e lúcida.

Essas provas das raisons de Rousseau são confirmadas por ele próprio. No Discurso sobre as ciências e as artes, ele afirma que o estudo corrompe os costumes dos homens, haja vista que “[...] altera sua saúde, destrói o temperamento e frequentemente destrói sua razão; mesmo que lhe ensinasse alguma coisa, eu o consideraria muito mal recompensado" (ROUSSEAU, 1999b, p. 299). Mas é nas Cartas morais que a distinção entre a razão e a razão raciocinante definitivamente sairá do campo, por assim dizer, ideológico da crítica de Rousseau atribuída ao dogmatismo religioso e aos philosophes do século XVIII para uma crítica no interior do entendimento. É possível traçarmos uma aproximação do que Rousseau (2005c, p. 149) chama de "raciocínio" ou a "má razão" com sua crítica à filosofia das Luzes:

[...] a arte de raciocinar não é absolutamente o mesmo que a razão: frequentemente é o seu abuso. A razão é a faculdade de ordenar todas as faculdades de nossa alma de forma adequada à natureza das coisas e suas relações conosco. O raciocínio é a arte de comparar as verdades conhecidas para compor a partir delas outras verdades as quais ignorávamos e que essa arte nos faz descobrir. Mas ele não nos ensina de modo algum a conhecer as verdades primitivas que servem de elementos às outras, e quando em seu lugar colocamos nossas opiniões, nossas paixões, nossos preconceitos, longe de nos esclarecer, ele nos torna cegos, não edifica a alma, mas exaspera e corrompe o julgamento que deveria aperfeiçoar.

Aqui a razão separa-se do raciocínio; a primeira tem o poder de julgar, e a segunda oscila de acordo com a variabilidade das opiniões humanas. Nesse sentido, na filosofia de Rousseau, são claros dois usos acerca da razão: o primeiro, positivo, está diretamente relacionado à organização e à elaboração do conhecimento humano; e o outro, relacionado ao raciocínio, é negativo e segue a orientação antropológica de Rousseau (1999a), que aponta que a razão perverteu o homem em sua "bondade natural" e o transformou em um "animal depravado".

Quanto a essa última crítica, podemos dizer que a relatividade do raciocínio torna evidente as peripécias da razão, mas não a razão prática e lúcida (raisonnable), e sim a razão teórica e especulativa (rationelle). Os philosophes pertencem ao negativo da razão, exatamente por induzir os homens a seus sofismas e os aprisionar na subjetividade turva da opinião e da ilusão. Derathé (2011) não confunde a razão raisonnable com a razão rationelle, por isso não reduz a razão ao raciocínio, e vice-

\begin{tabular}{|l|l|l|l|l|}
\hline Qovista Dialectus & Ano 8 & n. 15 & Agosto - Dezembro 2019 & p. $203-217$ \\
\hline
\end{tabular}


versa, como o faz Masson (1916). A bondade natural do selvagem serve a Masson; o retorno à natureza é a prova de que os instintos são mais seguros do que a pretensiosa razão. No entanto, a irracionalidade do homem selvagem, para Derathé (2011), é equivalente à falta interpretativa de Masson (1916), haja vista que, para ele, a razão aperfeiçoa os instintos primitivos e eleva o homem a uma condição superior em relação ao seu puro estado de natureza. Sua ideia positiva da razão é proveniente do papel central que essa faculdade exerce não apenas nos escritos metafísicos de Rousseau, como as Cartas morais, mas principalmente em seus escritos políticos ${ }^{11}$, nos quais a razão é um constituinte fundamental da vontade geral ${ }^{12}$.

Contudo, na Profissão de fé, Rousseau (2014, p. 410) pode nos levar a uma terceira solução interpretativa sobre a relação entre a razão e a consciência, exatamente aquela de que, sob certos aspectos, as ideias são sentimentos e os sentimentos são ideias, ou de que a razão se confunde com a consciência, e vice-versa:

[...] Os dois nomes convêm a qualquer percepção que nos ocupe tanto com seu objeto quanto com nós mesmos, que somos afetados por ele, apenas a ordem dessa afeição determina o nome que lhe convém. Quando ocupados principalmente com o objeto, só pensamos em nós mesmos por reflexão, trata-se de uma ideia; inversamente, quando a impressão recebida atrai nossa primeira atenção e só pensamos por reflexão no objeto que a causa, trata-se de um sentimento.

Aqui se desfazem as antinomias entre a razão e a consciência; Rousseau relativiza a atribuição ou o uso que se faz delas quando queremos solicitá-las. São as afeições que determinam como e de qual forma devemos nomeá-las. Nesse sentido, pensar no fora é pensar sobre nós mesmos, ou seja, refletir a partir de um "dentro" de si, ou o mesmo que criar uma ideia. Do contrário, pensar através de uma impressão recebida é pensar sobre nós através de um "fora", e é a isso que chamamos de sentimento. Talvez Derathé (2011, p. 174) se aproxime mais dessa possibilidade interpretativa, quando diz "[...] que a retidão do julgamento depende antes de tudo do direito do coração. Este é o ponto de vista de um moralista, para quem o coração e a

11 Goldschimidt (1983) faz uma dura crítica à entusiasmada interpretação racionalista de Rousseau por Derathé (2011). Para Goldschimidt (1983), Derathé (2011) confundiu o selvagem com o homem civilizado em potência.

12 Não são poucas as afirmações de Rousseau, em diversos de seus escritos políticos, sobre a importância da razão na consolidação do contrato social. Para ele, a razão cria o Estado: “[...] das luzes públicas resulta a união do entendimento e da vontade do corpo social, daí o perfeito concurso das partes e, enfim, a maior força do todo" (ROUSSEAU, 1999c, p. 108).

\begin{tabular}{|l|l|l|l|l|}
\hline Revista Dialectus & Ano 8 & n. 15 & Agosto - Dezembro 2019 & p. $203-217$ \\
\hline
\end{tabular}


razão não são duas faculdades rivais, mas devem, ao contrário, prestar-se um mútuo apoio".

Mesmo podendo ser relativizadas, as interpretações sobre a relação entre a razão e a consciência no interior da obra de Rousseau serão plausíveis, depende, sobretudo, dos olhares e da destinação que queremos realizar sobre a sua obra. Masson (1916) enxerga Rousseau como um defensor da religião natural, um romântico e, acima de tudo, um sentimentalista. Derathé (2011), para quem a influência dos filósofos racionalistas e dos teóricos do direito natural foram decisivas para Jean-Jacques, percebe sua filosofia como resultado de um esforço racional, em que resgatar a razão seria o mesmo que valorizar o seu otimismo no homem, principalmente sob o ponto de vista político. Essa possibilidade de uma interpretação perspectivista sobre o pensamento de Rousseau pode ser avaliada no interior de seu pensamento, como um artifício em que está inserido o seu ceticismo. Dessa forma, ele faz do uso da razão um instrumento contra a fé irracional da religião e, por vezes, utiliza do sentimento contra o dogmatismo das seitas filosóficas de seu tempo.

\section{REFERÊNCIAS:}

CASSIRER, Ernst. A questão Jean-Jacques Rousseau. São Paulo: Unesp, 1999.

BEAULAVON, Georges. La philosophie de J.-J. Rousseau et l'esprit cartésien. Revue de Métaphysique et Morale, Paris, v. 44, p. 325-352, 1937.

BRÉHIER, Émile. Les lectures malebranchistes de Jean-Jacques Rousseau. Revue Internationale de Philosophie, Paris, v. 1, p. 98-120, 1938.

DERATHÉ, Robert. Le rationalisme de Jean-Jacques Rousseau. Genève: Slatkine, 2011.

GOLDSCHIMIDT, Victor. Anthropologie et politique: les principes du système de Rousseau. Paris: J. Vrin, 1983.

GOYARD-FABRE, Simone. Politique et philosophie dans l'oeuvre de Jean Jacques Rousseau. Paris: PUF, 2001.

HUBER, Marie. Lettres sur la religion essentielle à l'homme: distinguée de ce qui n'en est que l'accessoire. Nouvelle édition revue et corrigée. Première partie. Londres, 1739.

MASSON, Pierre Maurice. La religion de J. J. Rousseau: la formation religieuse de Rousseau. 2. ed. Paris: Hachette, 1916.

\begin{tabular}{|c|c|c|c|c|}
\hline Rovista Dialectus & Ano 8 & n. 15 & Agosto - Dezembro 2019 & p. $203-217$ \\
\hline
\end{tabular}


KAWAUCHE, Thomaz Massadi. O essencial da religião em Marie Huber e J.J. Rousseau. Argumentos, Fortaleza, v. 4, n. 8, p. 115-123, 2012.

PITASSI, Marie-Cristina. Marie Huber, genevoise et théologienne malgré elle. Bulletin de la Société d'Histoire et d'Archéologie de Genève, Genève, v. 25, p. 83-96, 1995.

ROUSSEAU, Jean-Jacques. Carta a Beaumont. In: . Carta a Christophe de Beaumont e outros escritos sobre a religião e a moral. São Paulo: Estação Liberdade, 2005a. p. 37-117.

Carta ao Senhor de Franquières. In: Carta a Christophe de Beaumont e outros escritos sobre a religião e a moral. São Paulo: Estação Liberdade, 2005b. p. 175-190.

Cartas morais. In: - Carta a Christophe de Beaumont e outros escritos sobre a religião e a moral. São Paulo: Estação Liberdade, 2005c. p. 139-174.

Discurso sobre a origem e os fundamentos das desigualdades entre os homens. São Paulo: Nova Abril Cultural, 1999a.

Discurso sobre as ciências e as artes. São Paulo: Nova Cultural, 1999b.

Do contrato social. São Paulo: Nova Abril Cultural, 1999c.

Emílio ou da educação. 4. ed. São Paulo: Martins Fontes, 2014.

Fragmentos sobre Deus e a Revelação. In:

Beaumont e outros escritos sobre a religião e a moral. São Paulo: Estação Liberdade, 2005d. p. 191-215.

STAROBINSKI, Jean. Jean-Jacques Rousseau: a transparência e o obstáculo. São Paulo: Companhia das Letras, 2011.

\begin{tabular}{|l|l|l|l|l|}
\hline Q & Anoista & Agosto - Dezembro 2019 & p. $203-217$ \\
\hline
\end{tabular}

